\title{
GAZETECILIK ETIĞi ÜZERINE
}

\author{
Süleyman iRVAN*
}

Hürriyet gazetesi ombudsmanı Faruk Bildirici, ombudsman olarak yaptığı değerlendirmeleri Günahlarımızda Yıkandık: Örneklerle Gazetecilik Meslek Etiği adlı kitabında gazetecilere ve gazetecilik öğrencilerine başvuru kaynağı olabilsin diye 43 başlıkta ve anlamlı bir bütünlük içerisinde bir araya getirmiş. Kitabı değerlendirmeye geçmeden önce gazete ombudsmanlığı (ya da okur temsilciliği) üzerine birkaç söz söylemek isterim.

Türkiye'de gazete ombudsmanlığı kurumu 1999 yılında Milliyet ile başladı. Yavuz Baydar ilk ombudsman olarak adeta ombudsmanlığın ne olduğunu ve nasıl yapılması gerektiğini gösterdi. Faruk Bildirici Hürriyet'te ombudsmanlık yapmaya 2010 yılında başladı. Ben 2012 yılında KKTC'de Yenidüzen gazetesinde ombudsman olarak değerlendirmeler yapmaya başladığımda hem Baydar'ı hem de Bildirici'yi kendime örnek almıştım. Zorlandığım zamanlarda kendilerinden görüş istedim. Bazen de onlar benim görüşlerimi sordu. Bugün dört gazetede (Hürriyet, Sabah, Milliyet, Cumhuriyet) ombudsman var ve ben her hafta ombudsmanların yazılarını ilgiyle takip ediyor ve mümkün olduğunca da bu yazıları sosyal medya üzerinden paylaşıyorum, öğrencilerime de ombudsmanları takip etmeleri için öneriyorum.

Faruk Bildirici gazetecilik mesleği ve etiği konusundaki duyarlıı̆ına güvendiğim bir gazeteci. Bu kitap da baştan sona dikkatli biçimde okunması ve etik sorunlarla karşılaşıldığında başvurulması gereken temel bir kaynak niteliğinde. Umarım iletişim fakültelerinde etik dersleri veren meslektaşlar da bu kitabı öğrencilerine önerirler.

Faruk Bildirici, kitabın sunuş yazısında "günahlarımızda yıkandık, ama arınabildik mi?" diye soruyor. Her ne kadar, medyada etik sorunlar ortadan kalkmadıysa ve çeşitlenerek artıyorsa da, gazetecilik etiği konusunda bir bilinç düzeyi yakalandığını düşünüyorum. Özellikle sosyal medyanın katkısı yadsınamaz.

* Profesör Doktor, Üsküdar Üniversitesi, iletişim Fakültesi 
Diyelim ki bir gazete, yazarının yazısını web sayfasından uçurmuşsa (örneğin Hürriyet'te Cansu Çamlıbel'in başına gelenler), anında sosyal medyada eleştiri konusu oluyor, uçurulan yazı başka mecralardan paylaşılıyor.

Bu yazıda, Faruk Bildirici'nin kitabını okurken altını çizdiğim notlar çerçevesinde bir değerlendirme yapmaya çalışıım.

\section{Kuşku, gazeteciliğin olmazsa olmazıdır}

"Gazetecilik salt aktarma faaliyeti değildir. Öyle olsaydı bizim işimizi hoparlörler, kayıt cihazları gibi aygıtlar da yapabilir, belge açıklayan, aktaran herkes gazeteci sayılırdı" diyor Bildirici (2018: 23). Bu bölümde ilginç bir tartışma da başlatıyor Bildirici ve wikileaks'in bir gazetecilik faaliyeti olmadığını söylüyor: "Wikileaks'i gazetecilik faaliyetinden ayıran temel olgu, ele geçirdikleri belgeleri olduğu gibi yayınlamaları, üzerinde bir inceleme ve araştırma faaliyeti yürütmemeleriydi". Ancak ben Faruk Bildirici'yle aynı görüşte değilim bu konuda. Wikileaks belgelerini "sızıntı gazeteciliği" olarak tanımlamak ve veri gazeteciliği bağlamında meseleye bakmak gerekir diye düşünüyorum. Öte yandan, Faruk Bildirici'nin altını çizdiği etik ilkeyi de hatırlatmak istiyorum: Gazeteci elde ettiği her belgeden, bilgiden kuşkulanmalı ve doğruluğunu kontrol etmek için çaba göstermelidir.

\section{Ya ilk değilse?}

"Türkiye'de gazeteciler, "ilk" diye yazmayı çok sever" diyor Faruk Bildirici (2018: 33) ama bir uyarı da yapıyor: "ilk yazmak tehlikelidir. Çok emin olmadan, iyice araştırmadan 'ilk' diye yazmamak, söylememek gerekir. 'ilk' olduğu iddiasını ortaya atıp da yalanlanmak, bu kez haberin tümüyle değersizleşmesine, gazetecinin güvenilirliğini kaybetmesine neden olabilir" (2018: 34). Bildirici, Hürriyet'ten ilk olmayan ilk haberlerini örnek olarak gösteriyor. Medya da "ilk" haberlerini yayımlanmaya devam ediyor kuşkusuz. Örneğin 5 Temmuz 2018 tarihinde Ayşe Arman, Hürriyelt te yayımlanan Ferzan Özpetek röportajına "Dünyada bir ilk! Ferzan Özpetek'ten "WhataStar' sosyal medya yetenek yarışması" başlığını atınca, dünyada ilk kez sosyal medya üzerinden bir yetenek yarışması düzenleniyor olabilir mi acaba dedim. illk diye yazmak ilgi çekiyor ama ya ilk değilse?

\section{Ölüm haberleri nasıl verilmeli?}

Faruk Bildirici bu başlık altında ölüm haberlerinin nasıl verilmesi gerektiğini anlatıyor. "Biz gazetecilerin ölüm karşısında yapması gereken, saygı göstermektir. Hem de hiç ayrım yapmadan, her insanın ölümüne saygıyla yaklaşmalıyız. Ölüme saygı, yakınlarının acısına duyarlııkla başlar." Bildirici, Mehmet Ali Birand, Müslüm Gürses gibi tanınmış kişilerin hastanede yaşam savaşı verirken 
ölüm haberlerinin verildiğini, oysa gazetecilerin "bu haber ne kadar okunur" değil, "bu ölüm doğru mu" diye sormaları gerektiğini belirtiyor (2018: 40). Ayrıca, kaza haberlerinde, şehit haberlerinde, doğal felâketlerde ölüm haberlerinin, yakınları bilgilendirilmeden yapılmaması gerektiğinin altını çiziyor. Terör ve cinayet haberlerinde yaşamlarını yitirenlerin yakın plan fotoğraflarını kullanmamak, kanlı ve şiddet içeren görüntülere yer vermemek gibi önemli hatırlatmalar yapıyor.

\section{İsimler nasıl kodlanmalı?}

Bazı haberlerde kişi isimlerini açıkça yazmak sorunlu. Özellikle cinsel saldırı mağdurlarının, suça karışan ya da mağdur konumunda olan çocukların korunması gerekiyor. Gözaltına alınan yani zanlı konumunda olan kişilerin de masumiyet karinesi gereği isimlerini açıklamamak gerekiyor. Bildirici, "isimlerin haberde açıcça yazılmasının sakıncalarını bütün gazeteciler bilir. Fakat pratikte buna pek de dikkat edildiği söylenemez. Maalesef Türkiye'de isimlerin kodlanması ve fotoğrafların buzlanması konusunda hiçbir standart yoktur" diyor (2018: 49). Faruk Bildirici bu bölümde, güncellenmesinde benim de katkı yaptığım "isimlerin kodlanması ve fotoğrafların buzlanması kılavuzu”na yer veriyor (2018: 49). Bu kılavuz gerçekten de gazeteciler için önemli bir başvuru kaynağı niteliğinde.

\section{Intihar haberleri nasıl verilmeli?}

Faruk Bildirici intihar haberleri konusunda keskin bir çizgi çekiyor: "Intihar haberlerinin yayınlanmasında kamu уагагı olmadığı açıktır. Birinin intiharını öğrenmek kimseye bir şey kazandırmaz, kimseyi mutlu etmez. Ama intihar haberleri zarar verir. Çünkü intihar bulaşıcıdır" (2018: 57). Bildirici, ünlü olmayan insanların haberlerinin kesinlikle verilmemesi görüşünde. Ancak ben bu türden keskin bir set çekmenin sorunlu olabileceğini düşünüyorum. Örneğin, atanamayan öğretmenin intiharı elbette haber değeri taşıyor. Nitekim Hürriyet de diğer gazeteler gibi atanamayan genç öğretmenin intiharını 16 Nisan 2018 tarihinde "Atanamayan öğretmen intihar etti" başlığıyla vermişti. Elbette, intihar yöntemlerini ayrıntılı yazmamak, intihar haberlerini öyküleştirmemek gerekiyor. Tıpkı kaza haberleri için hazırlanan kılavuz gibi, intihar haberlerinin nasıl verilmesi gerektiği konusunda da ayrıntılı bir kılavuza ihtiyaç olduğu açık.

\section{Felaket haberciliği}

Felaketler doğaları gereği haber değeri yüksek olaylar. Deprem, sel felaketi, terör saldırıları gibi olayları haber yaparken özenli davranmak gerekiyor. Faruk Bildirici, bu başlık altında felaket haberciliğinde dikkat edilmesi gereken ilkelere değiniyor: "Gazeteci, felaket bölgesindeki insanların psikolojisini göz önüne almak zorundadır. Travma yaşamış, yakınlarını kaybetmiş, yaralanmış

\section{$190 \mid$ ETKILEŞiM | Yıl $1 \mid$ Sayı $2 \mid$ Ekim 2018}


insanlarla konuşurken onları daha fazla üzecek üslup kullanılmamalı..." (2018: 65). Bildirici, yazısında insan odaklı felaket haberciliğine özellikle vurgu yapıyor: "Bir felaketi izleyen gazeteci, felaketin sonuçlarının ortadan kaldırılmasına yardımcı olmalı. Bu da insana dair kaygıları felaket haberlerinin odağına almayı gerektiriyor" (2018: 68). Galiba asıl mesele de bu: Felaketleri yaşayanların insan olduklarını unutmamak.

\section{Kadınlara ilişkin haberleri erkek diliyle haberleştirmek}

Faruk Bildirici, kadınların konu olduğu haberlerdeki temel sorunları gayet iyi özetliyor: "Kriminal haberlerde kadınlar mağdur bile olsalar haberin baş öznesi olarak sunulurlar... kadın cinselliği haberin ambalajı haline getirilir. Erkeklerin kadına yönelik şiddeti ise 'kıskançlık', 'cinnet', 'aldatma' gibi sözcüklerle meşru gösterilir" (2018: 69-70).

Bildirici, yazısının sonunda kadın odaklı haberciliğin nasıl yapılması gerektiğini de maddeleștirmiş. Bir ilkeyi buraya alıyorum: "Kadına yönelik şiddet haberlerinde özendirici olmamalı, mazeret üretmemeli, örnek oluşturmamalıyı. Şiddet mağduru kadınları korumak için kimliklerini kodlayarak ya da fotoğrafını mozaikleyerek de olsa vermemeli, şiddet gösteren erkeği haberin öznesi haline getirmeliyiz" (2018: 77-78).

\section{Ayrımcılık ve nefret söylemi}

Gazetecilik meslek ilkeleri, her türden ayrımcılıktan ve nefret söyleminden uzak durulması gerektiğini önermesine karşın maalesef medyada ayrımcılık ve nefret söylemi giderek artmaktadır. Örneğin Hrant Dink Vakfı tarafından düzenli olarak yayımlanan Medyada Nefret Söylemi Raporu'na göre (Ocak-Nisan 2018), dört aylık sürede 3076 adet nefret söylemi içeriği tespit edilmiş. Gerçekten yüksek bir rakam. Faruk Bildirici, "Her gazeteci, gazetecilik mesleğini (etik) ilkeler ışığında yürütmek zorundadır. Bütün insanların eşit olduğu ve aralarında hiçbir ayrım yapılmaması gerektiği ilkesini benimsemeden gazetecilik yapılamaz. Hatta benimsemek de yetmez, bu ilkeleri içselleştirmek gerekir" diyor (2018: 81).

\section{Şiddet haberciliği}

Şiddet maalesef hayatın bir gerçeği ve haber değeri de yüksek. Faruk Bildirici (2018: 93), şiddet haberciliği konusunda şunları söylüyor:

Şiddete karşı önlem alınması, toplumun şiddetten arındırılması, çare aranması asıl olarak bu ülkeyi yönetenlerin işi. Gazeteciler de şiddete karşı kampanyalar yürütebilir, insanların bu yönde bilinçlenmesini sağlayıcı yayınlar yapabilir. Fakat daha önemlisi, medyanın toplumdaki şiddetin artmasına katkıda bulunmaması, şiddeti körükleyici yayınlar yapmamasıdır. 


\section{Terör haberleri nasıl verilmeli?}

Terör haberciliği netameli bir konu, çünkü Faruk Bildirici'nin de altını çizdiği gibi, devleti yönetenler terörle mücadelede gazetecilerin milli duruş sergilemesini, terör haberlerini yayımlamamasını, devletin zaaflarını görmezden gelmesini isterler. Bu bakış açısı ister istemez gazetecileri devletin propaganda aygıtı konumuna indirger. Oysa, "gazeteci, terör ve terörle mücadelede gerçekleri topluma aktarmakla yükümlüdür". Bildirici, bu uyarısının ardından terör haberleriyle ilgili evrensel ilkeleri hatırlatıyor: "Terörün propagandasına aracı olmamak, kan ve şiddeti toplumda travma yaratacak biçimde yansıtmamak, insanların acılarına saygılı davranmak" (2018: 105).

\section{Barış gazeteciliği mümkün mü?}

Barış gazeteciliği konusunda çokça yazmış ve barış gazeteciliğini savunan bir akademisyen olarak Faruk Bildirici'nin (2018: 115-116) barış gazeteciliği konusunda yazdıklarını önemsiyorum.

Barış gazeteciliğini sadece silahlı çatışmalar ve savaşların yaşandığı bölgelerde uygulanabilecek bir gazetecilik türü olarak kabul etmemek gerekir. Barış gazeteciliği, bütün haberlerde geçerli kılınması gereken bir gazetecilik yaklaşımı... Gazeteci hayatın her alanında barış̧ı olmalı ki, çatışmaların çözüme ulaşmasına yardımcı olabilsin. Barışı içselleştirmeden, çatışan taraflardan birinin tarafında yer alarak ve onların çatışmacı dilini benimseyerek barış sağlanamaz. Çatışmacı dil barışa hizmet etmez.

Bugünkü devletler arası çatışmalarda medyanın ateşe körükle giden haberciliğine bakınca, bu tespitlerin ne kadar doğru olduğunu görebiliyoruz. Çatışma dili çözümü de zorlaştırıyor.

\section{Masumiyet karinesini unutmamak}

Faruk Bildirici, bu başlık altındaki yazısına şöyle başlıyor: "Yargılamalarla ilgili haber yazarken hiç unutulmaması gereken temel ilke masumiyet karinesidir. Daha açık söylemek gerekirse, yargılanan herkes, hakkında mahkûmiyet kararı verilene kadar masum, yani suçsuzdur" (2018: 133). Gayet açık değil mi? Peki medya bu evrensel kuralı uyguluyor mu? Uygulamadığını Bildirici örneklerle gösteriyor.

\section{Ekonomi sayfaları şirket bülteni gibi}

Faruk Bildirici, ekonomi haberlerine eleştiriler yönelttiği yazısında şu tespitlerde bulunuyor:

Günümüzde ekonomi haberlerinin yönünü belirleyen, iş dünyası ve ekonomi yönetimi ile içlidışlı ilişkiler. Reklam verme gücü, haber değerini belirleyen ölçütlerden ilki haline geldi... İş dünyasındaki yanlışlar, eksikler, olumsuzluklar hakkında haber

\section{2 | ETKíleşim | Yıl 1 |Sayı 2 | Ekim 2018}


görmek neredeyse imkânsız. İnşaat, maden ve otobüs kazaları gibi durumlarda bile firma isimleri yazılmıyor (2018: 145).

Faruk Bildirici, bu bölümde, yazımında öncülük ettiği ve medya dünyasında büyük bir uzlaşmayla benimsenen "Trafik kazası haberleri yazım kılavuzu"na da yer veriyor.

\section{Reklam kokan haberler, reklam yapan yazarlar}

Bildirici, Ursula Le Guin'in edebiyat dünyasıyla ilgili eleştirisini gazeteciliğe uyarlayarak şunları yazıyor: "Günümüzde medyanın, piyasaya ürün pazarlama ile gazetecilik arasındaki farkı bilen gazetecilere ihtiyacı var. Medya kuruluşlarının satış ve reklam gelirlerini maksimize edecek satış stratejilerine uyan haberler üretmenin gazetecilikle ilgisi yoktur" (2018: 157). Doğru bir tespit değil mi? Faruk Bildirici bu bölümde sadece reklam kokan haberlere değil, gazetecilerin yeni ortakları haline gelen halkla ilişkiler uzmanlarına da dikkat çekiyor: "Türkiye'de...medya, reklamcıların yanı sıra bir de halkla ilişkiler ve iletişim danışmanlığı yapan şirketler ile uzmanlarının yönlendirmeleri, telkin ve tavsiyeleriyle karşı karşıya" (2018: 158). Bildirici, yazılarında reklam yapan Ayşe Arman, Ahmet Hakan gibi yazarları da eleştirmekten çekinmiyor.

\section{Bedava geziler körleştirir}

Faruk Bildirici, davet gazeteciliğini, hediyeleri ve bedava gezileri eleştirdiği bu bölümde önemli uyarılarda bulunuyor: "Davet gazeteciliği, gazetecilik meslek etiği açısından problemlidir. Çünkü gazetecilik gerçeği, ama yalın gerçeği hiçbir çıkar ilişkisine dayanmadan aktarma mesleğidir"; "Gazeteciye verilen hediyeler de...etik açıdan sorunludur. Çünkü gazeteci ile yayına konu edeceği kişi ya da kurumlar arasında maddi hiçbir ilişki olmamalıdır" (2018: 170); "Bu tip geziler, gazetecinin eleştirel bakmasını engelliyor. Oysa bir gazeteci eleştirel olmak durumundadır. Aksi halde yaptığı iş, gazetecilikten çok o şirketin tanıtım faaliyetine dönüşebilir" (2018: 171).

\section{Köşe yazarları da eleştirilebilir mi?}

Ombudsmanlığın en zor alanlarından biri, köşe yazarlarının eleştirilip eleştirilemeyeceği meselesidir. Sonuçta köşe yazarları haber yazmıyorlar, dolayısıyla ombudsmanın yorum yazılarına eleştiri getirmesi beklenmez. Ancak, eğer yazılarda nefret söylemi ve ayırmcılık söz konusuysa, şiddet özendiriliyorsa ya da yazarlar ticari kuruluşların reklam yıldızı oluyorsa, ürün reklamı yapıyorlarsa ombudsman eleştiri yapabilir. Faruk Bildirici, bu konuda net çizgiler çiziyor: "Hem reklamcl, hem gazeteci olunmaz. O nedenle de başta ABD ve Avrupa ülkeleri olmak üzere dünyada habercilerin, yazarların ve haberle ilgili editorial kadronun reklam yapmasına izin verilmez" (2018: 181). 


\title{
Haberlerin yüzde 70-75'i magazinleştiriliyor
}

Faruk Bildirici, Türk medyasında giderek artan magazinleşme meselesine de değiniyor. Güzel bir tanım da yapıyor: "Magazinleşme, siyasal, ekonomik, tarih, sosyal, sanat, spor gibi farklı alanlardan ciddi konuların işlendiği haberlerin sulandırılması, ikincil unsurlarının ön plana çıkarılarak 'eğlendirici' bir malzemeye dönüştürülmesidir" (2018: 189).

Bildirici, magazinleşmenin 1980'lerde ortaya çıktığını ve giderek artı̆̆ını ifade ediyor: "Magazinleştirilmiş haberlerin bütün haberler içerisindeki oranı yüzde 70-75'lere ulaştı" (2018: 189).

\section{Özel hayat ve kamu yararı dengesi}

Faruk Bildirici, evrensel bir gazetecilik ilkesi olarak kişilerin özel hayatlarına müdahale edilmemesi gerektiğini vurguladıktan sonra bazı istisnalardan söz ediyor:

Ancak toplumlarda bütün bireyler, özel hayatın gizliliği ilkesinden eşit oranda yararlanamaz. Ünlü kişiler, devlet adamları, politikacılar, resmi görevi olan bireyler ile bu tür konumda olmayan kişilerin özel yaşam alanları farklıdır. Ünlüler ve kamusal görevi olanların özel hayat alanları daha dardır. Toplumda tanınmış ve kamusal görevi olanlarla ilgili haberlerde, bu kişilerin özel yaşam alanı ile kamunun bilme hakkı ve basın özgürlüğü arasında denge gözetilir. Bu dengede temel ölçüt de kamu yararıdır. (2018: 201)

Elbette kamu yararı tanımlanması zor bir kavram. Bildirici bu kavrama açıklık getiren örnekler de veriyor. Ayrıca, oldukça önemli olan "mekânsal yalıtım" kriterinden de söz ediyor: "Kişinin yalnız olmasına güvenerek toplum önünde davranmayacağı şekilde hareket ettiği, kamunun gözü önünde olmayan alanlar olarak tanımlanıyor mekânsal yalıtım" (2018: 205).

\section{Gizli kayıtlar haber olursa?}

Faruk Bildirici, gizli kayıtlara dayalı habercilikte AiHM kararlarını hatırlatıyor.

\begin{abstract}
AiHM, gizli bir belgeyi 'kamu yararı' gerekçesiyle yayımlayan gazetecilerin 'iyi niyetli olmasını, olgulara dayanmasını, basın kurallarılla tutarlı, güvenilir ve belirgin haber vermesini' istiyor! Demek ki, toplumun yararına olmasının yanı sıra bir de gazetecilerin, o haberi hazırlarken temel gazetecilik kurallarına uymaları ve salt gerçeği insanlara aktarma güdüsüyle hareket etmeleri gerekiyor (2018: 213).

Bildirici'ye göre, gizli yöntemlerle elde edilmiş bir kayıt söz konusu olduğunda gazetecinin bakması gereken yer kimin rahatsız olacağı ya da kaydın yasal olup olmadığı değil, toplumun o bilgiyi öğrenmesinde kamu yararı olup olmadığı
\end{abstract} meselesidir. 


\section{Sağlık haberciliği nasıl olmalı?}

Faruk Bildirici, sağlık alanında yaşanan ticarileşme sonucunda sağlık haberciliğinin de giderek önemli hale geldiğini belirttikten sonra medyaya uyarılarda bulunuyor (2018: 249):

Okuru/izleyiciyi böyle bir bilgi kirliliğinden uzak tutmanın yolu, uzman ve deneyimli sağlık muhabiri istihdam etmek, piyasaya yönelik kaygılarla hareket etmeyen ve gerçekten uzman olan hekimlere alan açmak, sağlık haber ve yazılarında gazetecilik ve tıbbi etik ilkelerin uygulanmasına özen göstermek, en önemlisi de kamu çıkarını her tür ticari kaygının üzerinde tutmak gerekir.

\section{Internet haberciliğinin sorunları}

Faruk Bildirici, internet haberciliğine ayırdığı bölümde yaşanan temel sorunlardan söz ediyor: "...hız nedeniyle geleneksel gazeteciliğin haberleri kaynağından doğrulama ve bütün unsurlarını tamamlama ilkesi, dijital mecrada hakkıyla yerine getirilemez; yeterince araştırılmamış haberler yayına verilir"; "Türkiye'de internet medyasının bir de içerik üretememe gibi büyük bir zaafı bulunur. Küçük kadrolarla çalışan internet haber siteleri, gazeteler ve gazetelerin web sayfalarından 'kopyala-yapıştır' yöntemiyle çoğu zaman kaynak bile göstermeden içerik alırlar" (2018: 297). Bildirici yazıda tık avcılığı ve galeri haberciliğine de eleştiri getiriyor (2018: 301-302):

Elbette başlığın haberi okutmak, okuru çekmek için çarpıcı olması gerekli. Ama çarpıcı olsun ve okutsun diye haberin içeriği ile örtüşsmeyen başlık atılmamalı... Aynı şekilde, doğru düzgün bilgi içermeyen, sırf sayfa sayısını artırmak için uzatılan 'galeriler' de gazete-okur ilişkisini yıpratacak bir yöntem.

\section{Dijital arşivler ve unutulma hakkı}

İnternet yayıncılığı ile birlikte yeni sorunlar da ortaya çıktı. Bunlardan en önemlisi, internete konan içeriğin kalıc hale gelmesi. Haliyle insanlar kendileriyle ilgili bazı bilgilerin kalıcı olmasından rahatsızlık duyuyorlar ve bu haberlerin silinmesini istiyorlar. Faruk Bildirici, "unutulma hakkı" çerçevesinde bu işlemin nasıl yapılması gerektiğini anlatıyor. Bildirici unutulma hakkını, "dijital hafızada yer alan bireye ait fotoğraf, kimlik bilgisi, adres ve diğer kişisel içeriğin, yine bireyin kendi talebi üzerine bird aha geri getirilemeyecek biçimde silinmesi" olarak tanımlıyor. Bu bağlamda, Hürriyet gazetesinde uygulanmak üzere 2014 yılında hazırladığı "Dijital yayında düzeltme kılavuzu"na yer veriyor (2018: 309-310). Oldukça detaylı olan bu kılavuzu, internet üzerinden yayın yapan tüm medya kuruluşlarının benimsemesi ve uygulaması iyi olurdu.

\section{Haber fotoğrafçılığında etik ilkeler}

Yazısına, "Haber fotoğrafçılığı, ne sanat fotoğrafçılığına benzer ne de stüdyo 
fotoğrafçılığına. Risklidir, tehlikelidir, sabır işidir... Haber fotoğrafçılığı gazeteciliktir" diye giriş yapan Faruk Bildirici, Aylan bebek fotoğrafları gibi karelerin çokça tartışıldığını ve haber fotoğrafçılığı konusunda etik standartlar belirlemenin gerekli olduğunu ifade ettikten sonra Türkiye Foto Muhabirleri Derneği için geliştirdiği ancak henüz ortak bir metin olarak benimsenmemiş olan "Haber fotoğrafçılı̆̆ etik ilkeleri”ne yer veriyor. Bu belgenin foto muhabirleri ve editörler için yol gösterici nitelikte olduğuna kuşku yok.

\section{Seçilmiş gazeteciler}

"Özel davetleri Türkiye gazeteciliğine asıl yerleştiren Turgut Özal oldu" diyor Faruk Bildirici (2018: 387). Özal, Başbakanlığı sırasında bazı yazarlarla ve Ankara temsilcileriyle özel ilişkiler geliştirmiş ve haliyle de bu temsilci ve yazarlar habercilikte muhabirliğin önüne geçmeye başlamış. Demirel'in 1995 yılındaki bir Uzak Doğu gezisinden sonra tutum değiştirerek gezilerine gazetecileri ismen davet etmeye başladığını, davet edilenlerin de eleştirel haberler yazmayı bıraktıklarını anlatıyor. AK Parti döneminde hem Cumhurbaşkanı Abdullah Gül'ün hem de Başbakan ve ardından Cumhurbaşkanı olarak Tayyip Erdoğan'ın gazetecileri gezilere ismen davet ettiğini ifade ettikten sonra şu eleştirileri yapiyor (2018: 403):

Uçağa davet bir 'ödüllendirme' gibi kullanılıyor, bu davetlerle prestij kazandığını düşünen gazeteciler için de davetli listesinde var olmaya devam etme kaygısı habercilikten daha ağır basıyor. Fakat sonuçta, 'seçilmiş gazeteci' olmak, gazeteciliğin daha etkin biçimde yapılmasının kapılarını açmıyor, tam tersine gazeteciliğin iğdiş edilmesi, basın özgürlüğünün sınırlandırılması anlamına geliyor.

\section{Siyasete mesafeli duruş şart}

Faruk Bildirici, Türkiye'de gazetecilerin politikacılarla aralarında bulunması gereken mesafeyi koruyamadıklarını ifade ediyor: "Ne yazık ki, özellikle de iktidardaki politikacılarla içli dışlı olma hali AKP döneminde hayli yaygınlaştı medyada" (2018: 405). Kuşkusuz mesafe ortadan kalkınca haber de gerçeği aktarabilme işlevini yitiriyor. Bildirici'ye göre, "Bu duruma gelinmesinde siyasi iktidarın akreditasyon cezaları, cumhurbaşkanı ve başbakan ile gezileri de ödül olarak kullanması ve gazeteciler arasında 'bendensin / benden değilsin' ayrımı üzerine kurduğu ilişkinin de etkisi büyük" (2018: 405).

Faruk Bildirici'nin 430 sayfalık kitabında başka eleştirileri de var. Örneğin, iktidarların medyayı çeşitli yaptırımlarla hizaya getirmeye çalıştıklarını, demokrasi geliştikçe basın özgürlüğünün de genişlediğini ifade ediyor; Gazetecilik faaliyeti nedeniyle gazetecileri cezalandırmanın, en çok sayıda gazeteciyi hapse atan ülkeler sıralamasında birinci sırada olmanın yanlışlığını vurguluyor (2018: 414, 421).

Bu yazıyı Faruk Bildirici'nin kitaptaki son cümlesi ile bitirelim: "Özgürlüğün ol-

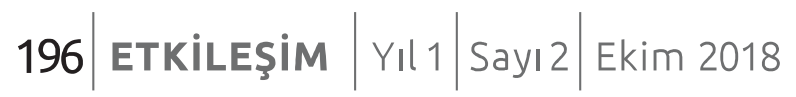


madığı yerde medya görevini yapamaz, kamuoyu da bilgi edinme hakkını kullanamaz."

\section{Kaynakça}

Bildirici, F. (2018). Günahlarımızda Yıkandık: Örneklerle Gazetecilik Meslek Etiği. ìstanbul: Ayrıntı Yayınları. 